\title{
Can 3-dimensional Ultrasound Change Gynecological Ultrasonographic Examination?
}

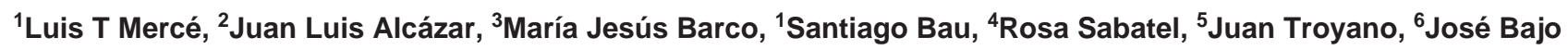 \\ ${ }^{1}$ Hospital Ruber Internacional, Madrid, Spain \\ ${ }^{2}$ Clínica Universitaria de Navarra, Pamplona, Spain \\ ${ }^{3}$ Centro Ginecológico Bolonia, Zaragoza, Spain \\ ${ }^{4}$ Department of Obstetrics and Gynecology, Granada University, Spain \\ ${ }^{5}$ Department of Obstetrics and Gynecology, La Laguna University, Tenerife, Spain \\ ${ }^{6}$ Hospital Universitario Santa Cristina, Madrid, España
}

Correspondence: LT Mercé, Enrique Leyra, 17. 28035 Madrid, España, e-mail: Itmerce@sego.es

\begin{abstract}
Objective: To verify whether 3D transvaginal ultrasonography is as accurate as 2D conventional ultrasonography and whether it provides additional advantages in gynecologic diagnosis.

Material and methods: We performed a prospective study in 46 women who underwent 2D and 3D transvaginal scans successively. Three 3D volumes (uterus and each ovary) were acquired and evaluated 4 months later on a personal computer. We compared 2D and 3D scans in relation to sonographic diagnosis and biometry and the time spent.

Results: There was complete agreement between 2D and 3D techniques for sonographic diagnosis (31 normal exams, 16 adnexal cysts and seven myomas), except for the visualization and measurement of the uterine cervix. The mean time for 2D scans was $3.29 \pm 1.32$ minutes and was $2.96 \pm 0.58$ minutes for $3 \mathrm{D}$ examination $(P=0.076)$. The time required to acquire 3D volumes was only 1 hour, freeing 1 hour and 32 minutes for the performance of new scans.
\end{abstract}

Conclusions: Transvaginal 3D ultrasonography can be more efficient than conventional 2D ultrasonography in gynecologic diagnosis.

Keywords: Ultrasound, efficiency, two-dimensional, threedimensional.

\section{INTRODUCTION}

Transvaginal sonography has become an essential tool for diagnosing gynecological pathology and its value has been wellestablished. ${ }^{1-5}$

Three-dimensional ultrasound has been recently introduced into clinical practice. ${ }^{6-8}$ Initially this technique focused on the acquisition of obstetrical images. However, its value in gynecological patients is currently under investigation. ${ }^{9-11}$

It has been speculated that this technique could change the way for performing ultrasound scanning in obstetrics and gynecology. It has been shown that this technique may reduce significantly examination time in obstetric and gynecological ultrasound scan. ${ }^{12-14}$

The aim of the present study is to assess whether threedimensional transvaginal ultrasound is as accurate as two- dimensional ultrasound and whether it provides additional advantages in diagnosing gynecological pathology.

\section{MATERIAL AND METHODS}

Forty-six consecutive and unselected women who attended our office between February and June 2006 participated in the present study.

Patient's mean age was 36 years, ranging from 16 to 52 years. Twenty-four (52.2\%) women were asymptomatic, eleven (23.9\%) presented with sterility, seven (15.2\%) presented with abnormal uterine bleeding and 4 (8.7\%) presented with pelvic pain.

After the nature of the study was fully explained all patients gave oral informed consent.

Diagnostic work-up included medical history and complete physical examination as well as pap smear.

Then 3D-transvaginal ultrasound was performed using a Voluson 730 Expert (GE Medical System, Milwaukee, USA) with a 3-9 MHz endovaginal probe and color, power and pulsed Doppler as well as 3D ultrasound capabilities. The same examiner (LTM) performed all examinations.

First a conventional 2D ultrasound scan was performed. The uterus was localized and measured in three orthogonal planes, including cervical length. Endometrial thickness was also measured in the longitudinal plane, including two endometrial layers at the level of its maximum thickness.

Any pathological finding was recorded. For example, in case of uterine fibroids, location and size was recorded. Then, adnexal regions were thoroughly scanned. The ovaries were identified and measured (only two diameters: longitudinal and anteroposterior). Follicles and/or corpus luteum were counted and their maximum diameter measured.

Any pathological finding in adnexal region was recorded. The functional status was established as follicular or luteal according to findings (follicular development and presence or not of corpus luteum). Total time spent for 2D ultrasound was recorded. 
Can 3-dimensional Ultrasound Change Gynecological Ultrasonographic Examination?

Once 2D US was finished, 3D volumes from the uterus and adnexal regions were acquired. We obtained three volumes: one for the uterus and one for each adnexal region. 3D volumes were acquired one after other immediately. Uterine volume was acquired in the longitudinal plane, including the whole uterus. $3 \mathrm{D}$ volume angle sweep was set at $90^{\circ}$.

For adnexal regions angle sweep was set at $60^{\circ}$. Acquisition time was 15-20 seconds per volume.

All three volumes were stoned in the ultrasound machine hard disk and subsequently transferred to a PC for offline assessment using the 4D-view software (GE Medical Systems, Milwaukee, USA).

In November 2006, this means five months after the last patient was scanned, stored 3D volumes were retrieved for analysis. This was done in such way in order to avoid possible recall bias derived from the immediate analysis after 2D ultrasound.

Each volume was manipulated according to MISUS group recommendations. ${ }^{15}$ The same measurements than those performed during 2D ultrasound were done.

Total time spent for manipulating the stored $3 \mathrm{D}$ volumes and performing measurements was recorded in each case. This time was added to the time spent for acquiring the three $3 \mathrm{D}$ volumes.

\section{STATISTICAL ANALYSIS}

We first compared the findings observed by $2 \mathrm{D}$ and $3 \mathrm{D}$ ultrasound. We assessed the agreement of findings between both methods.

Secondly we compared measurements obtained by 2D and 3D ultrasound and total time spent for both techniques, using student - t-test.

A p value $<0.05$ was considered as statistically significant.

\section{RESULTS}

Ultrasound findings for both techniques are shown in Table 1. There was an absolute agreement between both techniques.

Measurements for uterus and ovaries are shown in Tables 2 and 3. There were no statistical differences in these measurements. However, cervical length could only be measured in 33 (71\%) women using 3D ultrasound.

Total time spent was similar between both techniques (Table 4). However, time spent for scanning patients was significantly shorter using 3D ultrasound (92 minutes) than using 2D ultrasound (152 minutes) $(\mathrm{p}<0.001)$.

\section{DISCUSSION}

Three-dimensional ultrasound has a high reproducibility for calculating volumes and vascularity indices. ${ }^{16-18}$ Moreover, this technique has also showed some advantages for diagnosing fetal congenital abnormalities ${ }^{19,20}$ and gynecological tumors. ${ }^{21,22}$
Table 1: Sonographic diagnosis by 2D and 3D ultrasound

\begin{tabular}{lcc}
\hline Diagnosis & 2D US & $3 D$ US \\
\hline Follicular phase & 20 & 20 \\
Luteal phase & 6 & 6 \\
No pathology & 5 & 5 \\
Functional ovarian cyst & 2 & 2 \\
Endometriotic ovarian cyst & 4 & 4 \\
Simple ovarian cyst & 1 & 1 \\
Hydrosalpinx & 1 & 1 \\
Uterine fibroid & 5 & 5 \\
Adenomyosis & 1 & 1 \\
Retatined trophoblastic tissue & 1 & 1 \\
\hline
\end{tabular}

Table 2: Uterine measurements by 2D and 3D ultrasound

\begin{tabular}{llccl}
\hline & $N$ & $2 D$ US & $3 D$ US & P value \\
\hline Uterine longitudinal diameter* & 46 & $55.7 \pm 7.9$ & $54.4 \pm 8.1$ & 0.183 \\
Uterine transverse diameter* & 46 & $53.2 \pm 7.9$ & $52.1 \pm 9.1$ & 0.166 \\
Uterine anteroposterior & 46 & $41.8 \pm 8.7$ & $41.4 \pm 8.9$ & 0.237 \\
diameter* & & & & \\
Cervical length* & 33 & $27.4 \pm 7.4$ & $22.9 \pm 7.4$ & 0.001 \\
Endometrial thickness* & 46 & $9.4 \pm 7.8$ & $9.5 \pm 7.1$ & 0.615 \\
Mean fibroid diameter* & 7 & $27.9 \pm 14.3$ & $27.4 \pm 12.8$ & 0.646 \\
\hline
\end{tabular}

* All measurements expressed in millimeters

Table 3: Ovarian measurements by 2D and 3D ultrasound

\begin{tabular}{lllll}
\hline & $N$ & $2 D$ US & $3 D$ US & P value \\
\hline $\begin{array}{l}\text { Right ovary longitudinal } \\
\text { diameter* }\end{array}$ & 46 & $34.8 \pm 9.9$ & $35.3 \pm 9.4$ & 0.247 \\
$\begin{array}{l}\text { Right ovary transverse } \\
\text { diameter* }\end{array}$ & 46 & $20.3 \pm 7.1$ & $20.4 \pm 6.9$ & 0.820 \\
$\begin{array}{l}\text { Left ovary longitudinal } \\
\text { diameter* }\end{array}$ & 46 & $32.9 \pm 8.1$ & $33.4 \pm 8.6$ & 0.140 \\
$\begin{array}{l}\text { Left ovary transverse diameter* } \\
\text { Dominant follicle diameter* }\end{array}$ & 46 & $19.5 \pm 7.3$ & $20.6 \pm 6.3$ & 0.101 \\
$\begin{array}{l}\text { Corpus luteum diameter* } \\
\text { Mean adnexal cyst diameter* }\end{array}$ & 5 & $16.2 \pm 4.4$ & $14.9 \pm 4.3$ & 0.073 \\
\hline
\end{tabular}

* All measurements expressed in millimeters

Table 4: Mean time spent by 2D and 3D ultrasound

\begin{tabular}{lllll}
\hline & Mean & SD & Minimum & Maximum \\
\hline Total time 2D US* & 3.29 & 1.32 & 1.43 & 8.00 \\
Acquisition time 3D US* & 1.23 & 0.10 & 1.17 & 1.50 \\
Evaluation time 3D US* & 1.73 & 0.56 & 0.68 & 3.90 \\
Total time 3D US * & 2.96 & 0.58 & 1.85 & 5.23 \\
\hline
\end{tabular}

* Time expressed in minutes 
In the present study we have demonstrated that 3D ultrasound is comparable to 2D ultrasound for performing pelvic scan in gynecological patients. These findings are similar to those reported by Benacerraf et al. ${ }^{14}$

We found that cervical length could not be measured in $29 \%$ of the cases. This could be explained by the fact that insonation angle of the transvaginal transducer is not wide enough to allow the inclusion of the whole uterus (corpus and cervix). This was also pointed out by Benacerraf et al. ${ }^{14}$ For this reason they recommended to acquire 2 volumes for the uterus: one for the corpus and other for the cervix.

Regarding measurements, we have shown that there are no differences between 2D real time and 3D offline measurements for uterine, ovarian, follicular, endometrial diameters. This means that offline measurements in stored 3D volumes are as accurate as 2D real time measurements.

Regarding time spent for both techniques we did not find differences between total time spent for a 2D real time ultrasound scan and total time spent for 3D volume acquisition and analysis. However, we spent 2 hours and 32 minutes to scan 46 patients using 2D real time ultrasound but we only need one hour for acquiring 3D volume and one hour and sixteen minutes for analyzing volumes. This means that taking into account only the time used for acquiring $3 \mathrm{D}$ volumes, the ultrasound machine could be used for one hour and half for assessing additional patients.

In conclusion, transvaginal 3D ultrasonography is comparable to conventional 2D ultrasound but can be more efficient.

\section{REFERENCES}

1. Fleischer AC, Andreotti RF. Color Doppler sonography in obstetrics and gynecology. Expert Rev Med Devices. 2005;2:605-11.

2. Chu CS, Ribin SC. Screening for ovarian cancer in the general population. Best Pract Res Clin Obstet Gynaecol. 2006;20:30720.

3. McDonald JM, Modesitt SC. The incidental postmenopausal adnexal mass. Clin Obstet Gynecol. 2006;49:506-16.

4. Timot Tritsch IE. Transvaginal sonography in gynecologic office practice. Curr Opin Obstet Gynecol. 1992;4:914-20.

5. Cohen L. Should transvaginal ultrasound be performed at annual examination in asymptomatic women? Int J Fertil Womens Med. 2003;48:150-53.

6. Bonilla-Musoles F. Three-dimensional visualization of the human embryo: A potential revolution in prenatal diagnosis. Ultrasound Obstet Gynecol. 1996;7:393-97.

7. Merz E. Three-dimensional transvaginal ultrasound in gynecological diagnosis. Ultrasound Obstet Gynecol. 1999;14:81-86.

8. Kurjak A, Pooh RK, Mercé LT, Carrera JM, Salihagic-Kadic A, Andonotopo W. Structural and functional early human development assessed by three-dimensional and fourdimensional sonography. Fertil Steril. 2005;84:1285-99.
9. Raine-Fenning N. The role of three-dimensional ultrasound in assisted reproduction treatment. Ultrasound Obstet Gynecol. 2004;23:317-22.

10. Mercé LT. A modo de introducción: ¿qué aporta la ecografía y el Doppler tridimensional? En: Mercé LT, editor. Manual MISUS: Teoría y práctica de la ecografía y angiografía doppler tridimensional en obstetricia y ginecología. Madrid: HABE; 2006:1-6.

11. Benacerraf BR, Benson CB, Abuhamad AZ, Copel JA, Abramowicz JS, DeVore GR, et al. Three and 4-dimensional ultrasound in obstetrics and Gynecology. Proceedings of the American Institute of Ultrasound in Medicine Consensus Conference. J Ultrasound Med. 2005;24:1687-97.

12. Benacerraf BR, Shipp TD, Bromley B. How sonographic tomography will change the face of obstetric sonography: A pilot study. J Ultrasound Med. 2005;24:371-78.

13. Benacerraf BR, Shipp TD, Bromley B. Three-dimensional US of the fetus: volume imaging. Radiology. 2006;238:988-96.

14. Benacerraf BR, Shipp TD, Bromley B. Improving the efficiency of gynaecologic sonography with 3-dimensional volumes. A pilot study. J Ultrasound Med. 2006;25:165-71.

15. Grupo MISUS. Propuesta de estandarización de la ecografía y angiografía Power Doppler tridimensional en la exploración obstétrica y ginecológica de rutina. (Documento MISUS; Consenso de Barajas, 15 de abril de 2005). En: Mercé LT, editor. Manual MISUS: teoría y práctica de la ecografía y angiografía doppler tridimensional en obstetricia y ginecología. Madrid: HABE; 2006:169-79.

16. Mercé LT, Gomez B, Engels V, Bau S, Bajo JM. Intraobserver and interobserver reproducibility of ovarian volume, antral follicle count, and vascularity indices obtained with transvaginal 3-dimensional ultrasonography, power Doppler angiography, and the virtual organ computer-aided analysis imaging program. J Ultrasound Med. 2005;24:1279-87.

17. Alcázar JL, Mercé LT, García-Manero M, Bau S, López-García G. Endometrial volume and vascularity measurements by transvaginal 3-dimensional utrasonography and power Doppler angiography in stimulated and tumoral endometria. An interobserver reproducibility study. J Ultrasound Med. 2005;24:1091-98.

18. Mercé LT, Alcazar JL, Engels V, Troyano J, Bau S, Bajo JM Endometrial volume and vascularity measurements by transvaginal three-dimensional ultrasonography and power Doppler angiography in stimulated and tumoral endometria: intraobserver reproducibility. Gynecol Oncol. 2006;100:544-50.

19. Merz E, Welter C. 2D and 3D Ultrasound in the evaluation of normal and abnormal fetal anatomy in the second and third trimesters in a level III center. Ultraschall Med. 2005;26:9-16.

20. Martínez-Cortés L, Azumendi G, Comas C, Mercé LT. Diagnóstico de las malformaciones fetales mediante ecografía tridimensional. En: Mercé LT, editor. Manual MISUS: teoría y práctica de la ecografía y angiografía doppler tridimensional en obstetricia y ginecología. Madrid: HABE; 2006:127-34.

21. Kurjak A, Prka M, Bajo Arenas JM, Sparac V, Mercé LT, Corusic A, et al. Three-dimensional ultrasonography and power Doppler in ovarian cancer screening of asymtomatic peri-and postmenopausal women. Croat Med J. 2005;46:757-64.

22. Alcázar JL, Mercé LT, García-Manero M. 3D Power-Doppler vascular biopsy: A new method for predicting ovarian cancer in vascularized complex adnexal masses. J Ultrasound Med. 2005;24:689-96. 